\title{
RESENHA
}

HASSAN, Wail. Immigrant Narratives - Orientalism and Cultural Translation in Arab American and Arab British Literature. Oxford: Oxford University Press, 2010.

\section{Comparando: o modo orientalista de representar o mundo árabe}

José Luís Jobim ${ }^{1}$

Wail Sediq Hassan, Professor Titular de Literatura Comparada na Universidade de Illinois em Urbana-Champaign, tem marcado sua presença internacional no meio comparatista com um interesse particular sobre as representações do mundo árabe. Em relação ao Brasil, Hassan tem trabalhado esta representação na literatura e, mais recentemente, na teledramaturgia brasileira ${ }^{2}$.

Em 2010, Hassan publicou Immigrant Narratives: Orientalism and Cultural Translation in Arab American and Arab British Literature, no qual apresenta comparações entre: as recepções de autores árabes ou descendentes de árabes nos mundos anglófono e árabe; as opções dessses escritores ao se dirigirem a um público anglo-americano ou a outro; um quadro de referências (orientalista) e suas contrapartes; as representações do mundo árabe derivadas do Orientalismo e as representações árabes sobre aquele mundo.

Como se sabe, o livro Orientalism de Edward Said ${ }^{3}$ mostrou como o imperialismo praticado por potências ocidentais nos países árabes, além da faceta mais óbvia de controle da população e dos territórios, implicou também a elaboração de uma representação do mundo árabe, que tinha mais a ver com os colonizadores do que com os colonizados, e implicava uma imagem distorcida e negativa do mundo dos colonizados.

Em seu livro, Hassan considera que há uma distinção entre os escritores que vieram do mundo árabe para os EUA e a Grã-Bretanha. Há os de primeira geração, que chegam aos EUA ou ao Reino Unido vindos de países árabes, e os de segunda geração, que falam a língua e conhecem a cultura local, e que já desenvolveram uma espécie de biculturalismo, pelo seu conhecimento tanto da cultura do país de acolhimento quanto do mundo árabe. Também segundo Hassan, a questão da "terra natal", ou de sua concepção, estaria sempre no horizonte, quer no caso dos imigrantes, quer no caso dos já nascidos nos países anglófonos.

Para ele, as narrativas de imigrantes árabes americanos e britânicos inevitavelmente têm de lidar com representações preexistentes, tanto do Ocidente em relação ao Oriente, quanto o contrário. Embora estes escritores imigrantes tenham reivindicado uma posição privilegiada para avalizar (ou não) representações já existentes e/ou para criar ou questionar novas, não poderiam escapar do que Edward Said chamou de Orientalismo.

Para Hassan, os imigrantes árabes que escrevem em inglês encontram-se situados fora do "Oriente", assim como os Orientalistas europeus e norte-americanos, mas apresentam uma diferença relevante em relação a esses últimos: são originários do "Oriente", embora pertençam também ao "Ocidente" em função da imigração e da adaptação à cultura ocidental, e em função de sua condição de imigrados:

\footnotetext{
${ }^{1}$ Universidade Federal Fluminense - UFF, Niterói, Rio de Janeiro, Brasil; https://orcid.org/0000-0002-02716665;jjobim@id.uff.br

${ }^{2}$ Está no prelo, a sair pelas Edições Makunaima, Literatura e (i)migração no Brasil, livro organizado por ele e pelo professor Rogério Lima (UnB) sobre imigração e literatura, no qual o leitor brasileiro poderá ter acesso a estas duas facetas de seu trabalho.

${ }^{3}$ Tradução portuguesa: SAID, Edward. Orientalismo. São Paulo: Companhia de Bolso, 2007.
} 
Portanto, a sua posição representa uma fusão de duas instâncias clássicas do informante nativo e do especialista estrangeiro. Muitos viam esta posição como privilegiada, porque lhes permitia uma singular visão de dentro para fora não somente sobre o mundo árabe, mas também sobre seu país adotivo. De fato, alguns daqueles escritores, especialmente os que escrevem em árabe e inglês, posicionaram-se não somente como intérpretes do "Oriente" para o "Ocidente", mas também como intérpretes do "Ocidente" tanto para ele próprio quanto para o "Oriente" - quer dizer, como tradutores nos dois sentidos. (Hassan, 2010, p. 29)

Hassan argumenta que não é possível escapar da presença do Orientalismo, como quadro de referência hegemônico no mundo anglófono, derivado de políticas imperialistas, de modo que implicita ou explicitamente os imigrantes árabes tiveram e têm de lidar com esta ideologia, e com as mudanças por que ela passou e continua passando, desde o século XIX até depois do ataque às torres gêmeas em Nova Iorque, em 11 de setembro de 2001. Assim, ao longo de vários capítulos em que analisa autores e autoras árabes de diferentes procedências e com diferentes interesses temáticos, demonstra que, seja para reiterar a representação "orientalista" do mundo árabe, seja para contestá-la, os escritores e escritoras sempre têm diante de si, no ambiente anglo-americano, o Orientalismo como elemento incontornável, configurador de representações sobre o "Oriente".

No caso destes escritores(as) árabes de língua inglesa, Hassan considera que a escrita de imigrantes é uma "literatura menor", no sentido que Deleuze e Guatari deram a esta expressão - uma literatura que uma minoria linguística produz, dentro de uma língua maior, o que geraria um efeito, mesmo em narrativas supostamente mais "individuais", como as autobiográficas: "O pessoal é sempre coletivo e as preocupações do indivíduo são compartilhadas por outros membros da minoria, de novo por causa das pressões sociais da maioria." (p. 5) No entanto, Hassan também aponta a limitação daqueles autores franceses para analisar as narrativas de imigrantes: "A teoria de Deleuze e Guatari não faz aquela distinção entre minorias imigrantes e não imigrantes, uma limitação que restringe sua utilidade não somente para as literaturas árabes, mas também para as literaturas de outras etnias de imigrantes." (p. 5)

Para Hassan, os imigrantes árabes teriam sempre de lidar com um quadro de referências "orientalista", através do qual o Ocidente representava a si como superior ao Oriente por várias razões alegadas (raça, cultura, capacidade mental etc.) que "faltariam" ao inferior, e seu livro apresenta um quadro diversificado, em termos temáticos e históricos, de como narradores árabes negociaram com este quadro de representações.

Um dos muitos méritos de Immigrant Narratives é o de fazer análises tanto de autores amplamente conhecidos, como Kahlil Gibran (1883-1931), como de desconhecidos para o grande público, demonstrando que, embora haja muitas diferenças entre cada caso particular, há também analogias e pontos comuns.

Gibran, que pertencia ao grupo conhecido como poetas imigrantes, famoso na cena literária árabe por viver em Nova Iorque, é certamente o autor mais conhecido no Brasil, embora neste país ele fosse visto como um indivíduo e não como membro de um grupo. Hassan fornece ao leitor o contexto para a compreensão do sentido da obra de Gibran: este grupo foi afetado pelo Orientalismo, aceitando a dicotomia Ocidente/Oriente, e, sob influência da depreciação da cultura árabe, e com carência de uma formação cultural propriamente árabe mais sólida, recorreu a referências "ocidentais" que não figuravam no repertório de autores árabes: “...eles introduziram o poema em prosa, além de uma forma e uma dicção mais simples, e [não era surpresa, portanto] que a influência de Rousseau, Blake, Wordsworth, Keats, Shelley, Emerson, Whitman e Nietzsche (os escritores de quem estavam mais próximos) tendia a ser desproporcional, para não dizer anacrônica, em relação à história literária Euro-Americana." Poderíamos aqui fazer um paralelo deste anacronismo com os romances machadianos, de 1881 
em diante, nos quais Machado de Assis teve como referência privilegiada um autor inglês (Lawrence Sterne) cuja obra e cujas técnicas literárias eram "anacrônicas" em relação ao momento no qual escreveu seus romances - momento marcado pelo Realismo e pelo Naturalismo. ${ }^{4}$

Anteriormente, eu já escrevi que só é possível dizer que alguma coisa é anacrônica se o caráter passado dela for visível no momento presente do público que fez a atribuição de anacronismo, pois dizer que uma coisa é anacrônica implica, entre outras coisas, designá-la como diferente de outras que, neste presente, são vistas como contemporâneas, pertencentes $e$ adequadas ao tempo presente. No caso de Machado de Assis, por exemplo, até 1902 sua circulação se limitou ao público lusófono, e as obras consideradas contemporâneas, pertencentes e adequadas ao tempo presente para aquele público eram basicamente as que atendiam a pressupostos (cor local, adesão ao Realismo/Naturalismo etc.) que aquele autor não seguia. No caso dos poetas imigrantes, Hassan parece apontar para o fato de que, enquanto algumas referências e técnicas ocidentais podiam ser vistas como "anacrônicas" no Ocidente, ao mesmo tempo podiam ser novidade na cultura árabe. E a possibilidade desse duplo e contraditório julgamento se dá justamente porque a obra circula em culturas diferentes, no mesmo momento histórico, nas quais é concomitantemente considerada como inovadora e anacrônica ${ }^{5}$, o que abre um imenso potencial de discussões no âmbito do comparatismo.

Embora tenha um título que remete a um corpus específico, o livro de Hassan, assim como anteriormente o de Said, ao falar do mundo árabe em relação ao "Ocidente" levanta um grande número de questões pertinentes e instigantes para os comparatistas e passou a ser leitura obrigatória, especialmente para os interessados em como o chamado "primeiro mundo" produz representações de seu "outro".

\section{REFERÊNCIAS}

HASSAN, Wail. Immigrant Narratives - Orientalism and Cultural Translation in Arab American and Arab British Literature. Oxford: Oxford University Press, 2010.

\& LIMA, Rogério. Literatura e (i)migração no Brasil. Rio de Janeiro: Makunaima, 2020. (No prelo.)

JOBIM, José Luís. La circulation littéraire/culturel et l'anachronisme. Revista Brasileira de Literatura Comparada, v. 21, p. 13-22, 2019.

ROCHA, João Cezar de Castro . Machado de Assis: Toward a Poetics of Emulation. 1. ed. East Lansing: Michigan State University Press, 2015.

SAID, Edward. Orientalismo. São Paulo: Companhia de Bolso, 2007.

\footnotetext{
${ }^{4}$ Cf. ROCHA, João Cezar de Castro . Machado de Assis: Toward a Poetics of Emulation. 1. ed. East Lansing: Michigan State University Press, 2015.

${ }^{5}$ Sobre esta concepção de anacronismo, cf. JOBIM, José Luís. La circulation littéraire/culturel et 1'anachronisme. Revista Brasileira de Literatura Comparada, v. 21, p. 13-22, 2019.
} 
José Luís Jobim, pesquisador do CNPq e Cientista do Nosso Estado (FAPERJ), é Professor Titular aposentado da Universidade Estadual do Rio de Janeiro, sendo atualmente Professor Titular na Universidade Federal Fluminense. Entre seus livros mais recentes, podemos citar: Dialogues France-Brésil - circulations, représentations, imaginaires (Com M. E. Chaves de Melo e E. Martin. Pau: Presses de 1’Université de Pau et des Pays de l’Adour, 2018), Portugal segundo o Brasil (Com Roberto Acízelo de Souza. Lisboa: Theya, 2018), Literary and Cultural Circulation (Oxford: Peter Lang, 2017); Literatura e cultura: do nacional ao transnacional (Rio de Janeiro: Editora da Universidade do Estado do Rio de Janeiro, 2013).

Submetido em 12/01/2020

Aceito em 25/03/2020 